\title{
Environmental and economic benefits of Integrated Product Service Offerings quantified with real business cases
}

\author{
Mattias Lindahl, Erik Sundin and Tomohiko Sakao
}

\section{Linköping University Post Print}

\section{Tweet}

N.B.: When citing this work, cite the original article.

Original Publication:

Mattias Lindahl, Erik Sundin and Tomohiko Sakao, Environmental and economic benefits of Integrated Product Service Offerings quantified with real business cases, 2013, Journal of Cleaner Production.

http://dx.doi.org/10.1016/j.jclepro.2013.07.047

Copyright: Elsevier

http://www.elsevier.com/

Postprint available at: Linköping University Electronic Press

http://urn.kb.se/resolve?urn=urn:nbn:se:liu:diva-96759 


\title{
Environmental and Economic Benefits of Integrated Product Service Offerings Quantified with Real Business Cases
}

\author{
${ }^{1}$ Mattias Lindahl*, ${ }^{2}$ Erik Sundin, ${ }^{1}$ Tomohiko Sakao \\ ${ }^{1}$ Department of Management and Engineering, Environmental Technology and Management, \\ Linköping University \\ ${ }^{2}$ Department of Management and Engineering, Manufacturing Engineering, Linköping \\ University \\ SE-581 83 Linköping, Sweden \\ e-mail: [mattias.lindahl, erik.sundin, tomohiko.sakao]@liu.se \\ ${ }^{*}$ Corresponding author: $+46-13-28-1108$
}

\begin{abstract}
This paper quantifies environmental and economic benefits of the Integrated Product Service Offering (IPSO) in real practice from a life cycle perspective, in comparison with its corresponding product-sales type business as a reference. The paper also discusses the engineering activities contributing to those effects, as well as their enablers. To reach this goal, the paper investigates three IPSOs as real-life business cases in industry. Those cases are selected from different sectors and have different characteristics. In addition, the paper calculates and compares environmental impacts and economic costs of different offerings in each case through the use of Life Cycle Assessment and Life Cycle Costing, respectively. In all three cases, IPSOs had environmental and economic advantages in comparison with the product-sales type business. The engineering activities contributing to those advantages under IPSOs were recycling, remanufacturing, reuse, maintenance, and holistic planning and operation. The enablers were found to be high flexibility for realizing products and services and close relationships with relevant actors.
\end{abstract}

Keywords - Integrated Product Service Offering (IPSO), Product Service System (PSS), Life Cycle Assessment (LCA), Life Cycle Costing (LCC)

\section{Introduction}

Increased competition and new customer requirements have led a number of manufacturers to strive towards selling what is known as the Product Service System (PSS) (e.g. Mont (2002), Tukker and Tischner (2006)). The PSS is a system combining physical products and services that 
have been integrated and optimized from a lifecycle perspective in relation to customer value (modified from Meier et al. (2010)). A variety of concepts and terms have been proposed referring to this type of offering or business in a broad sense such as total care product, functional sales, hybrid offering, integrated solution, and service/product engineering, in addition to PSS (e.g. Alonso-Rasgado et al. (2004), Windahl and Lakemond (2006), Sakao et al. (2009), Ulaga and Reinartz (2011)). This paper uses a term, Integrated Product Service Offering (IPSO), in referring to this type of business offering in order to emphasize the integration aspect.

IPSO research in the literature has several origins, one of which is research on environmental sustainability. Many researchers have emphasized that IPSOs facilitate dematerialization of society and stimulate design of products that are beneficial for the environment (e.g. Stahel (1994), Mont (2002), Sundin and Bras (2005) and Sakao and Shimomura (2007)). Among others, Tukker (2004) wrote one of the few papers showing that PSS can contribute to reducing environmental impacts semi-quantitatively, although most papers describe mainly qualitative, generic studies. However, even where the studies show positive results, it is not clear how much can be earned quantitatively by IPSOs in environmental and economic terms.

Thus, the paper quantifies and discusses environmental and economic effects of concrete IPSOs in practice in comparison with the product-sales type business based on Sundin et al. (2010). In doing so, it also aims to show what engineering activities contribute to those effects, as well as their enablers. To accomplish this, it investigates three real-life business cases in industry, calculating environmental impacts and economic costs of different offerings in each case using Life Cycle Assessment (LCA) and Life Cycle Costing (LCC).

The remainder of this paper consists of the following. Section 2 reviews existing literature and describes the paper's motivation, while Section 3 presents its goal and method. Next, Section 4 presents the results of the three case studies. Finally, Section 5 discusses the results before Section 6 concludes the paper.

\section{Motivation}

The IPSO has attracted industry (see e.g. Sakao et al. (2008)) based on its economic potential (Wise and Baumgartner, 1999) as well as the expectation of its environmental superiority (Tukker, 2004). In the study of IPSOs, various lines of research have been achieved to support companies to address these emerging types of offerings. Production research suggested changes required for how to design (and produce) an offering - from addressing service as an add-on to addressing dynamic interdependencies of product and services (e.g. choosing 
material characteristics suitable for a given service) (e.g. Meier et al. (2010)). Engineering design research has proposed several design methods, which are often formulated as generic procedures without specifying concrete engineering activities (e.g. Alonso-Rasgado et al. (2004), Maussang et al. (2009), Sakao and Lindahl (2012)).

In the marketing and management areas, a number of distinctive, generic capabilities (e.g. in risk management, design and sales) and success factors for this type of business have been suggested (e.g. Windahl and Lakemond (2006), Ulaga and Reinartz (2011)). Looking at the area of environmental sustainability, almost two decades ago Stahel (1994) noted the contribution of the service economy to environmental sustainability. A series of papers followed (e.g. Mont (2002), with Mont etal. (2006)) clarifying the PSS concept and its implications for environmental impact. In addition, only a few engineering activities forming IPSOs, such as remanufacturing (e.g. Sundin and Bras (2005)), have been argued to be beneficial from the environmental and economic views. In summary, only little insight is available regarding which concrete engineering activities contribute to IPSOs.

Although the literature has emphasized that IPSOs can create benefits for the environment, most of this research is at a qualitative level. The few papers that go beyond arguing PSS' qualitative contribution to reduce environmental impacts include van den Hoed (1997) cited in Roy (2000), which briefly reports the effects of shared utilization of a clothes washing service. Among others, a large laundry service could achieve a factor 10 reduction in water consumption by 2025 due to the efficiencies of scale and availability of skilled operators. Another case, , briefly described in Manzini et al. (2003), describes a utility company selling heat by combining solar energy and methane, but not invoicing the methane consumed to get the heat. The paper describes without details that in this case it is expected to reduce 100 tons of $\mathrm{CO}_{2}$ emissions per year. In a more systematic analysis, Tukker (2004) investigated eight types of PSS from the environmental viewpoint. Among others, the type "functional result" in the "result-oriented service", in which a provider and its customer agree with a result regardless of the adopted products or services, has the highest potential (up to a factor of 10). However, the analysis of this paper is based on a semi-quantitative study and the results are shown in a generic manner, i.e. without the presentation of concrete calculations. Yet another study by Lelah et al. (2011), on the other hand, has quantified the environmental benefits of a specific and concrete case of PSS belonging to the "functional result" with details. The addressed PSS replaced materials (truck and fuel) with a service (gathering information, which has less environmental impact than truck and fuel) so that the benefits include an $84 \%$ reduction in the category of global warming. Yet, there is a need for more concrete case studies to gain more insight into this area: What are, for instance, common enablers available in industry at present 
for a better environment and economy across different cases or sectors?

Even though the IPSO has attracted industry mainly because of its economic potential, the economic benefit of the IPSO for a provider has not been published and discussed in the literature. Therefore, there is a clear need for publishing more research quantifying the environmental as well as economic benefits of various IPSO cases in order to advance the scientific knowledge in this area.

\section{Goal and Methods}

This paper aims to describe the environmental and economic benefits of multiple, concrete cases of IPSOs in a quantitative manner in comparison with the traditional product sales approach. In doing so, this paper also aims to show what engineering activities contribute to those effects and what the enablers are for them, because this real insight supports designers with developing IPSOs in addition to the already-proposed generic design methods mentioned above.

To do so, this paper adopts the multiple-case study method, as it typically provides a stronger base for theory building (Eisenhardt and Graebner, 2007), and because more cases are needed in this area as explained above. The cases are derived from real offerings in practice in industry. In addition, each IPSO is identified so concretely that its constituents (e.g. maintenance frequency) in a contract are specified. The environmental impacts and economic costs of the offerings in each case are calculated by LCA (ISO 14 040, 1997) and LCC. In addition, literature reviews, semi-structured interviews and questionnaires have been performed in order to get information used for example in performing LCA and LCC; for more information, see Section 4.

\section{Case Studies}

\subsection{Overview}

This section describes the case studies conducted at three IPSO providers. In each case study, different offerings for both IPSOs and traditional product sales were identified and quantified based on their environmental impact and the economic cost for the providers.

Table 1 shows the offerings compared in each case study. Importantly, all of the IPSOs (Offering C) addressed in the case studies are offered today by the case companies, i.e. those IPSOs are in use industrially. All of the Offerings B are not available on the market at present. The reason why the Offerings $B$ are included in the comparison is to describe which factors contribute more to the differences between Offerings $A$ (traditional product sales) and C (IPSOs). The 
features of Offering B, including its business model, were determined based on the interests of those factors.

Literature studies, semi-structured interviews and questionnaires with the company staffs were the methods used for gathering data about the cases. This is because individual sources have not been able to supply data for the entire life cycle, and in order to confirm data that has been considered uncertain. Strong trust between the authors and participating companies, built over many years, has enabled unique access to data that are considered to be business secrets in many companies. These data have been carefully managed and agglomerated so that the final results do not reveal sensitive secrets, yet maintain the sufficient sources for scientific argumentation.

Nevertheless, in case appropriate data is not available, realistic assumptions were made in dialogue with those companies. It should be noted that the assumptions with IPSO were always defined so as to underestimate, rather than overestimate, the IPSO benefits. This means that IPSO benefits are more likely larger in reality.

In order to be able to make accurate comparisons between different offerings, each offering's environmental impact and cost were individually calculated. Unless something else is stated in the case descriptions below, each case includes production, logistics, use and end-of-of life treatment. If a component, process, activity or similar were considered by several sources - e.g. literature or company staffs - to represent less than $2 \%$ (LCA) and $5 \%$ (LCC) of the total, they were not included in the analysis unless numbers were easily available. Equal parts of e.g. components and processes were excluded unless it gave a disadvantage for the IPSO.

The environmental impact assessment was done with Eco-indicator 99 version 2.06 (Ministry of Housing Spatial Planning and the Environment, 2000) and the Intergovernmental Panel on Climate Change's (2007) characterization factors for $\mathrm{CO}_{2}$-equivalents. However, since the focus is on relative differences between different case studies' offering alternatives, measured in percent, no absolute numbers are presented.

\subsection{Case Study I-Core Plugs for Paper Mills}

\subsubsection{Company and business}

Polyplank $A B$ has developed a process to transform plastic waste and wood fibers into a cheap, recyclable and moisture-resistant composite material (Polyplank ${ }^{\circledR}$ material) used in different system solutions, one of which is the core plugs used by paper mills (Larsson, 2009a; Sundin et al., 2010). Paper mills use them to plug the cores on which paper is rolled up; thus, the core plugs follow the roll out to the customer. The core plug shown in Figure 1 has been developed 
in close cooperation with the customer.

By selling through the concept of IPSO, Polyplank collaborates closely with their customer, the paper mill, and can thus take advantage of the core plugs when the paper mill's customers send them back to the paper mill. Normally, the core plugs go back and forth several times between the paper mill and their customers before the plugs return to Polyplank. When a core plug is returned from the paper mill's customer, it is washed and checked before reuse, as seen in Figure 2.

There are three main offerings for the paper mill's customers' used core plugs:

- Reuse by the paper mill (sent out to new customers) - The most common offering is when core plugs, after a period out at the paper mill customer, are returned to the paper mill; after washing and quality control, these core plugs can be reused for new customers. If the core plug is worn out, it is returned to Polyplank where it is recycled. Normally, the core plug is reused several times. Because of their business model, Polyplank aims to achieve a level of quality that will enable their core plugs to be reused several times. Even the paper mill's customers benefit from this approach; instead of the cost and handling associated with discarding core plugs, they can easily send them back.

- Recycling by Polyplank - When core plugs are finally discarded, they are returned to Polyplank where they are ground down and sent to injection molding in order to become new core plugs. In practice, almost $100 \%$ of all incoming used core plugs are recycled into new core plugs.

- Disposal by the paper mill's customer - In a negligible number of cases (less than $0.5 \%$ ), used core plugs at the paper mill customer disappear or are discarded.

\subsubsection{Functional unit and compared offerings}

The functional unit in this study is the service a paper mill has of supplying a core plug used for paper rolls, which is sent to a customer once for a single use. The main difference between the different offerings is the number of times the core plug's material is reused, and how many times the mill can use the core plug before it is sent back to Polyplank for recycling. The different offerings are listed below, followed by Table 2 which describes the different offerings. In Offering A, virgin plastic is used in order to compare the pros and cons of Polyplank materials based on recycled plastics.

- Offering A: This offering corresponds to the traditional production of core plugs and is a competitor to Polyplank's core plug offering.

- Offering B: The paper roll with the core plug is only used once.

- Offering C: The paper mill customer returns the core plug back to the paper mill company 
where it is reused four times before it must be replaced. It is assumed that all replaced/discarded core plugs are returned to Polyplank, which through its recycling process reuses the material for new core plugs. It is also assumed that each plug can be recycled twice before the material eventually must be discarded (in reality, it is possible to reuse the material more times). This belongs to the type of functional result found within result-oriented service (Tukker, 2004).

\subsubsection{Delimitations and System Boundaries}

The largest delimitation is that any residual handling of core plugs beyond the core plug recycling process is not included. This delimitation is based on the fact that core plugs (both with virgin plastic and with Polyplank material) have a positive heat value when incinerated.

Waste management is not included other than from a material recycling perspective. The wood chips used in the Polyplank material are based on modified wood pellet data, in which carbon dioxide bound in the wood is ignored (Werner et al., 2007). If carbon dioxide were included, it would imply that the more wood the product consists of, the lower the environmental impact. Furthermore, material and energy used for producing machines, e.g. for core plug production, are not included.

Finally, various costs such as salaries are not included, and fixed costs of buildings and machinery are not considered. The reason for this is that these are estimated to be quite similar for all the investigated offering alternatives.

\subsubsection{Summarized results of LCA and LCC}

The compilation of the LCA and LCC is presented in Figure 3. Offering A is set as a reference. The comparison shows that there is a clear correlation, both environmentally and economically, between the choice of materials, recycling rate and reuse rate for a core plug.

The comparison clearly shows that if Polyplank would apply the sale of traditional core plugs as Offering A shows, it would also impact the environment and cause the cost to increase significantly compared with the current IPSOs that Offering $C$ represents. This is where today's IPSO represents an environmental load of $9 \%$ (Eco-indicator points) / $24 \%$ ( $\mathrm{CO}_{2}$-eq) and a cost of $11 \%$ compared to traditional selling.

\subsubsection{Discussion of results from LCA}

The LCA results are discussed in relation to choice of materials and recycling rate. The largest gain with Polyplank's offering is from the system for reuse of core plugs - the more times it is reused, the larger the gain. The second biggest gain is related to the recyclability of the 
Polyplank material. However, the more times the material is recycled, the smaller the positive economic and environmental effects become. This is because the major environmental and economic gain is from the initial cost of material that is avoided as long as the material can be recycled. Nevertheless, in combination, both gains imply a significantly reduced overall environmental impact compared with Offerings $A$ and $B$. The more times the material of the plug can be reused and recycled, the less the environmental impact. Polyplank's IPSO-based sales have increased its ability to take full advantage of its materials.

Since the Polyplank core plug can be reused the overall environmental impact per use is decreased; however, reusability puts higher requirements on quality regarding durability. It has been confirmed that the core plug that Polyplank manufactures has sufficient quality to withstand at least five reuses, which helps to reduce the overall environmental impact. If Polyplank would not work under IPSOs and instead focus on selling more plugs, it would result in an increased environmental impact. To summarize, Polyplank's IPSO-based selling helps to increase the possibility that the core plug reuse rate will increase.

Given the close cooperation between Polyplank and the paper mill, Polyplank can recycle core plugs, leading to a reduction in material consumption. The result shows that this gives a reduction in environmental impact compared to core plugs produced with virgin materials. The result also shows that the more times a core plug is recycled, the more the environmental impact is reduced.

\subsubsection{Discussion of results from LCC}

To clarify, the LCC results are discussed for the different offerings, such as differences in choice of materials and recycling rate. The use of recycled instead of virgin plastic reduces the life cycle cost.

When the paper mill does not need to consume as many core plugs, the life cycle cost per core plug is lower each time it is reused. From a traditional marketing perspective, this may in the short term be seen as something negative because it reduces demand for new core plugs. However, the interesting thing to consider is that since Polyplank can offer a core plug that has a lower cost per use, they have been able to take an increased market share.

\subsection{Case Study II - Cleaning of Building Exteriors}

\subsubsection{Company and business}

Based on their in-house developed method, Qlean Scandinavia AB cleans e.g. building exteriors as one of its businesses. The so-called Qlean ${ }^{\circledR}$ method consists of cleaning with Qlean water ${ }^{\circledR}$ (QW), as described in Lindahl et al. (2013). In the Qlean method, normal tap water (with some 
extra filtering seawater can also be used) is purified in a process so it becomes more or less completely free of by-products such as salt, lime, minerals and metals. QW has a conductivity of about 3-4 $\mu \mathrm{S} / \mathrm{m}$ (Lindahl et al., 2013). When QW comes into contact with a building exterior, it not only loosens dirt, algae and exhaust fumes, but also functions equally well on grease and oil.

When cleaning buildings, the design of the building and type of building exterior affects the application, and there are various options to facilitate work. Extended nozzles for washing equipment, sky lifts, and moveable or fixed scaffolding are all examples of tools that facilitate the cleaning of facades. Figure 4 shows application of the ultra-clean water by piping with nozzles. Despite the application method, to get the maximum power of the $\mathrm{QW}$, the Qlean method is always implemented from top to bottom on the facade. This means that the consumption of QW and the time for washing is highest at the beginning of exterior cleaning. Hence, the QW flows down the facade to loosen up the dirt and other undesirable materials, even on surfaces that do not have nozzles directed towards them. The Qlean method does not allow moisture to penetrate deep into the exterior wall, so painting can take place as soon as one day after cleaning.

When the wall is to be painted after washing, it is advantageous to use a scaffold, which is mounted on the wall, making it easier for the painter.

\subsubsection{Functional unit and compared offerings}

The functional unit in this study is the cleaning of $1 \mathrm{~m}^{2}$ of building exterior (Larsson, 2009c). To identify the economic costs and environmental impacts of building exterior cleaning, three offerings were identified. Offerings and assumptions for each were determined based on consultation between the authors and Qlean Scandinavia AB. Common to all offerings is that the building exterior cleaning requires the use of scaffolding and a staffing of two people during the entire cleaning operation. After drying, scaffolding that was used in the facade cleaning remains until it is painted. The different offerings are listed below, followed by Table 3, which shows the differences between the offerings (Larsson, 2009c).

- Offering A: In the traditional sale of building exterior cleaning, the customer first turns to a paint company to order building exterior painting. The painters then estimate the time based on the drying time of a traditional building exterior washing with detergents and high-pressure water (implying higher water consumption in comparison with the Qlean method), which is equivalent to six to ten working days. In the next step, the customer contacts a company that provides facade cleaning. The customer must schedule when the cleaning of the building exterior should be performed in order to permit enough time for 
drying prior to painting. A day's cleaning corresponds to a cleaned surface of $300 \mathrm{~m}^{2}$ with a drying time of six days.

- Offering B: The building exterior is cleaned by staff that rent QW equipment from Qlean Scandinavia $A B$, and thus the Qlean method applies, and the building exterior cleaning is sold through a traditional sales model. This means that the client's planning is still based on the painter's understanding concerning a drying time of six days. This offering also denotes that the company which rented the $Q W$ equipment does not have time to clean as many square meters as the Qlean Scandinavia AB staff would have covered. A day's cleaning corresponds to a cleaned surface of $250 \mathrm{~m}^{2}$.

- Offering C: Qlean Scandinavia AB offers the customer a clean and dry building exterior one day after cleaning. This is conducted with the Qlean method using a piping system with nozzles. A day's cleaning corresponds to a cleaned surface of $300 \mathrm{~m}^{2}$. This belongs to the type of functional result within the result-oriented service (Tukker, 2004).

\subsubsection{Delimitations and System Boundaries}

The environmental impact of the used contaminated water is not included. The reason for this is that all offerings will imply contaminated water, and are estimated to have the same impact on the ground unless the contaminated water is treated. Offering A will imply more water than Offerings $B$ and $C$. Furthermore, all offerings require a scaffold and this is therefore excluded from the analysis. The environmental impacts for machines only are estimated based on their material content.

\subsubsection{Summarized results of LCA and LCC}

A compilation of the LCA and LCC results are presented in Figure 5.

Offering $A$ is set to be the reference value and thus become the offering that all offerings are compared with. The results clearly show that it is environmentally preferable to use the Qlean method compared with the high-pressure water method. To make it cost-rate motivational to switch methods, the drying time needs to be included, as in Offering C. By applying Offering C, which includes short drying times for a customer, the customer can schedule painting earlier, and thus reduce the cost for renting scaffolding.

\subsubsection{Discussion of results from LCA}

The LCA highlighted several uncertainties surrounding the calculation, as discussed below. It was hard to find data about the building exterior detergent; instead, data based on assumptions and the detergents' content was collected and aggregated from several databases. However, some detergent data was not found and was left out of the study. Therefore, it is 
likely that the building exterior detergents' environmental impact is higher. This would imply that the high-pressure water wash is even worse in comparison with the Qlean method.

A small supply pump is used when applying the $Q W$, and it is uncertain to what extent the estimated supply pump is in line with reality. For example, to be on the safe side, it was calculated to be used on maximum load. The calculations still show that the supply pump's environmental impact is minimal in comparison with other calculated environmental impacts.

\subsubsection{Discussion of results from LCC}

The LCC brought to light several potential uncertainties. During the study, different assumptions and uncertainties were tested, but since the results were not significantly affected, it was decided to only discuss them here.

When a wall is flushed with high-pressure water, there is a risk of delicate parts breaking and loosening. It is a question of who is liable, how extensive the damage is and the cost of repairing it. However, because of low-pressure technology, the risk of building exterior damage does not exist for the Qlean method.

As in the LCA discussion, there are uncertainties about the supply pump's actual cost. However, since the energy use results in a negligible cost compared to the whole, the result is still considered to be valid. Labour costs are based on an estimate of the wages at Qlean Scandinavia $A B$. When wage variations occur, the result may change.

\subsection{Case Study III - Compacting soil}

\subsubsection{Company and business}

Swepac International AB (Swepac) is a Swedish manufacturer of soil compactors (illustrated in Figure 6). A soil compactor is used to compact mainly soil in order to create a strong base. Swepac offers various types of soil compactors to its customers, which for the most part consist of equipment rental companies for construction sites. Swepac aims to produce soil compactors that can withstand tough conditions in difficult environments. The company provides its customers with a fast supply of spare parts, technical service and support, as well as offering pure service agreements where customers have a list of service levels to choose from.

The way that the soil compactors are transported between the stakeholders is illustrated in Figure 7. At first Swepac design and manufacture the soil compactor. Secondly it is transported to the rental firm who rents it out to a construction firm. When service and remanufacturing is needed and/or scheduled the soil compactor is transported back to the rental firm and finally Swepac for service and/or remanufacturing. After service and/or remanufacturing it is ready 
for use once again.

In order to prolong the technical and economic lifetimes of its soil compactors, Swepac also conducts maintenance and remanufacturing. Remanufacturing could also be included in the customers' service agreement. The remanufacturing process generates costs for Swepac, which they are trying to reduce; Swepac's designers, for example, are working to minimize maintenance and remanufacturing costs by choosing a smart design for their products. Having the remanufacturing operation within the company, Swepac take the opportunity for cross-fertilization between the design and remanufacturing departments. Swepac strives to increase its soil compactors' lifetime and leasability. This effort has resulted in several design improvements, some of which are interchangeable eyebolts, protective moldings and materials (Sundin et al., 2009). The plan for Swepac designers is to develop soil compactors which have longer service intervals, and components and materials will be chosen to ensure that they last throughout a normal life cycle. In this research, the soil compactor called FB 250 was adopted, see Figure 8.

A soil compactor's technical and economic lifetimes differ, especially in comparison with its leasability. It is easiest to get new machines, which makes it likely that the rental firm can maintain a higher price on those. This is valid as long as the customer, i.e. user, has a greater willingness to pay for the new machines than the older. That the client would rent a new soil compactor before renting an older one is partly to avoid problems in service, but also for more psychological reasons (it feels better to work with new and refreshed equipment). The context (e.g. misuse and irresponsible use) in which soil compactors are used in general reduces the overall leasability to be shorter than the technical lifetime. This means that the rental firm probably has more functional machines in its inventory that can only be rented at a lower price, or when newer machines are already leased.

\subsubsection{Functional unit and compared offerings}

In this study, the functional unit was compaction of soil corresponding to a distance of one meter at a width of $0.55 \mathrm{~m}$; in other words, the functional unit is $0.55 \mathrm{~m}^{2}$ of compacted soil (Larsson, 2009b). The offerings were discussed after consultation between staff at Swepac and the authors. The differences between the various offerings are described in the section below, after which the various offerings are presented more clearly. Only Offering A applies the traditional sale model, while the other offerings assume IPSOs. The different offerings are listed and summarized in Table 4 below.

- Offering A: Swepac only manufactures and sells soil compactors through traditional selling. This means that technological innovations that increase the technical lifetime are not valid. 
The offering does not include any remanufacturing, which adversely affects the lifetime of the compactors' components. The color wear and other wear makes the soil compactors look unattractive after five years.

- Offering B: This offering is an IPSO Swepac had previously, and includes the repainting and remanufacturing of machinery. By remanufacturing and repainting, the leasability is extended to six years. The product-sales business model with e.g. galvanized surface could have been chosen for Offering B in the same manner as Cases I and II, but was not. Such an offering is less feasible in practice because the case company does not have sufficient incentive to galvanize the surface with the product-sales model. The interest in the offerings' feasibility was prioritized in specifying the features of Offering B.

- Offering C: To increase longevity and avoid repainting, the paint in this offering has been replaced by galvanized steel. In order to compare how the galvanizing and varnishing are different, it was determined in consultation with Swepac that the soil compactor's leasability is eight years.

Offerings $B$ and $C$ belong to the type of the product lease used within the use-oriented service (Tukker, 2004).

\subsubsection{Delimitations and System Boundaries}

In this study (Larsson, 2009b), it is assumed that the rental firm's goal is to maximize its profits by hiring out soil compactors at as high a price as possible. This implies that considerations have only been taken towards estimated leasability and technical lifetime linked to repair and maintenance needs. The leasability assumes the number of years the soil compactor can be rented out without lowering its price.

The study has not included costs incurred when a soil compactor breaks down and when the work is delayed. However, it should be regarded as self-evident that higher costs and reduced revenues will be incurred when the repairs must be performed, and hence it should be an endeavor to reduce the risk that soil compactors will break. It was found that the IPSO helps to gradually reduce this risk. In addition, the cost of transportation is not included in the study. It is then the rental company which is responsible for these costs, and such costs vary depending on where the rental company is located.

\subsubsection{Summarized results of LCA and LCC}

The compilation of the LCA and LCC is presented in Figure 9. Offering A was set to be the reference value and thus become the offering that all offerings are compared with; the comparison shows that there is a clear correlation, both environmentally and economically, between traditional sales and IPSOs. The offerings involving varnish (Offerings A and B) have a 
greater environmental impact than Offering $C$, that has galvanized parts, as illustrated in Figure 9. In addition, Offering $C$ is also preferred from an economic perspective.

\subsubsection{Discussion of results from LCA}

The results of the LCA were influenced largely by the leasability that applies to each offering. Generally, the results show clearly that the longer the leasability the soil compactor is assumed to have, the less environmental impact per square meter of packed soil. With IPSOs, there is an increase in the motivation to provide a product with optimal leasability.

Since Swepac performs remanufacturing and has established good relationships with rental companies, it creates better familiarity for how soil compactors perform in operation and which parts need replacing. Swepac works on reducing the need for repairs and remanufacturing by sharing its knowledge with rental firms and by gradually making improvements.

One improvement that Swepac has made is to galvanize selected components. The LCA result shows that zinc used for galvanization can provide a greater environmental impact. It should be noted that data for both painting and repainting show that the environmental impact is limited, e.g. no transport to and from repainting are included in the results. However, the leasability increases from 6 to 8 years, thus overcoming the increased environmental impact from the galvanization process.

It is difficult to give a full picture of what portion of total environmental impact the repairs account for. A faulty component does not directly lead to preventing the soil compactor from working, but if not addressed it might imply that other more vital components are damaged. The need for repair depends on external factors such as handling during use.

In the LCA, shipments have been handled carefully. However, it is difficult to know how often transportation to and from the repair is needed, and who in Offering A performs the repair. It should be seen as self-evident that the more repairs, the more transportation, and that more transportation will lead to greater environmental impact. In addition, many of the transports of the different offerings are equal and cancel each other out in the comparison.

\subsubsection{Discussion of results from LCC}

A rental service should strive to be able to rent a soil compactor as long as it can get the same benefit as the renting of a new one. Through remanufacture and implementing measures that make soil compactors look like new, the number of years a soil compactor can go out to the customer not only increases, but also the number of years it may go out to the customer at a higher price. Thus, it is in the rental company's best interest to have a leasability perspective. In 
this case, the result shows that soil compactors using the IPSO are, in the long-term, a better option than buying into the traditional forms of selling.

Through remanufacturing, Swepac creates cross-fertilization to product development; by adapting soil compactors to facilitate remanufacturing, the lead time for the remanufacturing process is reduced. With remanufacture, knowledge is created about the conditions for developing better products, with less need for repair and a longer lifetime.

The study found that IPSO and zinc coating for the galvanization of soil compactors is better in environmental and economic terms. It is clear that Swepac most likely would not have galvanized certain components if they did not use the IPSO approach. The IPSO approach has given Swepac enough drive to change their design to better fit their way of doing business. The reduction of cost in remanufacturing and maintenance made it cost-effective to galvanize certain components to avoid the costs incurred in the repainting process, as well as increase the lifetime and thus the leasability of the soil compactors.

\section{Discussion}

\subsection{Quantified benefits and the contributing engineering activities}

In all three cases it was found that the IPSO improves both the environmental and economic aspects compared with the traditional offering. The degree of improvement, however, differed among the cases. Case Study I showed approximately a $90 \%$ decrease (i.e. a factor of 10 ) both in the LCA and LCC. Case Study II showed, for the LCA part, a 98\% Eco-indicator points decrease (i.e. more than a factor of 10 ) and a $76 \% \mathrm{CO}_{2}$-eq decrease, and for the LCC part, a $66 \%$ decrease. Case Study III had for the LCA part a 26\% Eco-indicator points decrease and a $32 \%$ $\mathrm{CO}_{2}$-eq decrease, and for the LCC part, a 37\% decrease. It should be noted that, as mentioned in Section 4.1, components or processes were excluded unless they were disadvantageous for the IPSO. Furthermore, assumptions with the IPSO were always defined so as to underestimate, rather than overestimate, the IPSO benefits.

The main contributions in each case are summarized as follows. Case I includes the so-called "result-oriented service" (see Tukker (2004)), reuse/recycle, and the durable material contributing to the financial situation of the provider. Case II includes the unique washing method using no detergents and a holistic planning and operation. It should not be forgotten that the cleaning service is primarily a "process-oriented offering", and in general can be relatively easily contracted as a result-oriented service (see Tukker (2004)), which also facilitated the adoption of this unique technology. Case III includes prolonged lifetime and 
leasability with remanufacturing and an adjusted way of treating the surface of the product. The IPSOs (Offerings B and C) in Case III belong to the type of product lease within the "use-oriented" service (Tukker, 2004).

The results from the case studies are in line with previous qualitative research arguing that the IPSO approach is preferable from an environmental as well as an economic perspective (e.g. Mont (2002)). If a provider bears the cost of maintenance, repair, etc., they are motivated in developing durable products with a low maintenance cost and a long lifetime. This was shown in Cases I and III. In addition, if an IPSO provider keeps the ownership or control of a product during the use phase (i.e. knows they will get them back after use) and takes responsibility for keeping the product in good condition, it facilitates reuse and recycle of the product and its components. This also was true in Cases I and III. These can be termed as a higher commitment by an IPSO provider on more phases of a life cycle in comparison with the traditional business, when the provider transfers responsibility to the customer/user after the sales phase.

Regarding the environmental benefit, a similar trend is found in (Tukker, 2004). Cases I and II belong to the type of "functional result" found in result-oriented service and provide a radical reduction. Case III is a product lease and also retained a reduction of environmental impact and costs. A value of the paper lies in its quantification with concrete cases using real data figures. From these three case studies, it is not possible to draw a general conclusion that the IPSO is always preferable from an environmental perspective. However, the cases do show how IPSOs contribute to the environment and the financial situation of a company, including the relevant engineering activities in these three examples in real practice and in quantitative terms.

Those engineering activities contributing to advantages of IPSOs were design, recycling, reuse, maintenance, holistic planning and operation. The question of if these activities are facilitated by IPSOs is discussed in detail in Lindahl and Sakao (2013). It should also be emphasized that the IPSOs in all the cases are real offerings available in the marketplace. This means that various challenges associated with IPSOs can actually be overcome.

\subsection{IPSO Enablers}

The three cases are nominated from different sectors and have different characteristics. Nevertheless, some common factors are found across those cases. First, the contract type of offerings that have high flexibility for realizing products or services is an enabler, especially for substantial improvement. This was especially true in Cases I and II. For instance, in Case II the customer need lies in the cleanness and dryness of a building exterior, and knowing how to realize it. The greater freedom leads to more possibility - this is natural. However, it should be emphasized that it is not only a technology that is the contributor, but also engineering 
activities (e.g. service activity in Case II) and product characteristics (e.g. product structure in Case I), which are carefully designed in combination with the technology to achieve the radical change.

Another enabler is close relation with relevant actors. This was especially found in Cases I and III. In Case I, close contact between the supplier and customer has led to offerings customized and improved to better suit the customer. In Case III, the manufacturer needs to work close to their customers, who are leasing out their equipment, in order to adapt both product (with design improvements) and service organization for the IPSO.

The above is in line with earlier research by (Bartolomeo et al., 2003), which showed three factors influencing the success of eco-efficient producer services (EEPS):

1) development of innovative technology,

2) desire to form deeper relationships with customers, and

3) role of increased asset utilization.

What this paper has added to this earlier research is the identification of a driver (high flexibility in Cases I and II) for the first factor (i.e. innovative technology) and enrichment of the third factor (i.e. increased asset utilization). According to (Bartolomeo et al., 2003)), asset utilization meant employing unused products intensively and/or efficiently. However, this paper showed that design, recycling, remanufacturing, reuse, and holistic planning and operation contribute to improved environmental performance, and that all of these can be regarded as asset utilization at various levels (information, material, part or product). In Case I, design, recycling, and reuse mainly contributed to the environmental performance. In Case II, a holistic planning and operation were the main contributors. In Case III, they were mainly design and remanufacturing.

\section{Conclusion and future work}

This paper presented the calculations made for three cases of IPSOs on the market, both environmentally and economically. The results from these cases showed that the IPSO is preferable in comparison with traditional product sales approaches. The engineering activities contributing to those advantages under the IPSO were design, recycling, reuse, maintenance, holistic planning and operation. It should be noted that these activities are facilitated by IPSOs. The enablers were found to be high flexibility for realizing products and services and close relationships with relevant actors. Future work includes, besides more LCA and LCC studies of IPSO cases, a longitudinal and in-depth analysis of IPSE activities that would uncover more insights. In doing so, targeting design in such analysis would be interesting, as design was 
touched upon as an important activity in Section 5.2.

\section{Acknowledgements}

The authors would like to thank the Swedish Governmental Agency for Innovation Systems (VINNOVA) for partially financing the research, as well as all the participating companies for their efforts and providing valuable data. Henrik Larsson from Linköping University has contributed to the quantification of the cases.

\section{References}

Alonso-Rasgado, T., Thompson, G., Elfström, B.-O., 2004. The design of functional (total care) products. Journal of Engineering Design 15, 515-540.

Bartolomeo, M., dal Maso, D., de Jong, P., Eder, P., Groenewegen, P., Hopkinson, P., James, P., Nijhuis, L., Örninge, M., Scholl, G., Slob, A., Zaring, O., 2003. Eco-efficient producer services-what are they, how do they benefit customers and the environment and how likely are they to develop and be extensively utilised? Journal of Cleaner Production 11, 829-837.

Eisenhardt, K.M., Graebner, M.E., 2007. Theory Building from Cases: Opportunities and Challenges. Academy of Management Journal 50, 25-32.

Intergovernmental Panel on Climate Change, 2007. IPCC Fourth Assessment Report: Climate Change 2007 (www.ipcc.ch/publications_and_data/ar4/wg1/en/ch2s2-10-2.html).

ISO 14 040, 1997. Environmental Performance Evaluation - Life Cycle Assessment - Principles and Framework. International Organization for Standardization, Geneva, Switzerland.

Larsson, H., 2009a. Kartläggning av miljö- och kostnadsfördelar som ett Integrerat Produkt- och TjänsteErbjudande av en hylsplugg ger jämfört med traditionell försäljning, LIU-IEI-R-- 09/0076--SE. Industriell miljöteknik, Institutionen för ekonomisk och industriell utveckling, Linköpings universitet, Linköping,Sweden.

Larsson, H., 2009b. Kartläggning av miljö- och kostnadsfördelar som ett Integrerat Produkt- och TjänsteErbjudande av en markvibrator ger jämfört med traditionell försäljning, LIU-IEI-R-09/0077--SE. Industriell miljöteknik, Institutionen för ekonomisk och industriell utveckling, Linköpings universitet, Linköping,Sweden.

Larsson, H., 2009c. Kartläggning av miljö- och kostnadsfördelar som ett Integrerat Produkt- och TjänsteErbjudande av fasadtvätt ger jämfört med traditionell försäljning (in Swedish), LIU-IEI-R-09/0075--SE. Industriell miljöteknik, Institutionen för ekonomisk och industriell utveckling, Linköping, Sweden.

Lelah, A., Mathieux, F., Brissaud, D., 2011. Contributions to eco-design of machine-to-machine product 
service systems: the example of waste glass collection. Journal of Cleaner Production 19, 1033-1044.

Lindahl, M., Sakao, T., 2013. Environmental and Economic Contribution of Design Changes in Integrated Product Service Offerings, in: Meier, H. (Ed.), Product-Service Integration for Sustainable Solutions. Springer, Bochum, Germany.

Lindahl, M., Svensson, N., Svensson, B.H., Sundin, E., 2013. Industrial Cleaning with Qlean Water - A Case Study of Printed Circuit Boards. Journal of Cleaner Production 47, 19-25.

Manzini, E., Vezzoli, C., 2003. A strategic design approach to develop sustainable product service systems: Examples taken from the 'environmentally friendly innovation' Italian prize. Journal of Cleaner Production 11, 851-857.

Maussang, N., Zwolinski, P., Brissaud, D., 2009. Product-service system design methodology: from the PSS architecture design to the products specifications. Journal of Engineering Design 20, 349-366.

Meier, H., Roy, R., Seliger, G., 2010. Industrial Product-Service Systems - IPS². CIRP Annals Manufacturing Technology 59, 607-627.

Ministry of Housing Spatial Planning and the Environment, 2000. Eco-indicator 99 Manual for Designers A damage oriented method for Life Cycle Impact Assessment, Hague, Netherlands.

Mont, O., Singhal, P., Fadeeva, Z., 2006. Chemical Management Services in Sweden and Europe: Lessons for the Future. Journal of Industrial Ecology 10, 279-292.

Mont, O.K., 2002. Clarifying the concept of product-service system. Journal of Cleaner Production 10, 237-245.

Roy, R., 2000. Sustainable product-service systems. Futures 32, 289-299.

Sakao, T., Lindahl, M., 2012. A value based evaluation method for Product/Service System using design information. CIRP Annals - Manufacturing Technology 61, 51-54.

Sakao, T., Napolitano, N., Tronci, M., Sundin, E., Lindahl, M., 2008. How Are Product-Service Combined Offers Provided in Germany and Italy? - Analysis with Company Sizes and Countries -. Journal of Systems Science and Systems Engineering 17, 367-381.

Sakao, T., Shimomura, Y., 2007. Service Engineering: a novel engineering discipline for producers to increase value combining service and product. Journal of Cleaner Production 15, 590-604.

Sakao, T., Shimomura, Y., Sundin, E., Comstock, M., 2009. Modeling Design Objects in CAD System for Service/Product Engineering. Computer-Aided Design 41, 197-213.

Stahel, W.R., 1994. The Utilization-Focused Service Economy: Resource Efficiency and Product-Life Extension, The Greening of Industrial Ecosystems. National Academy Press, Washinton DC.

Sundin, E., Bras, B., 2005. Making functional sales environmentally and economically beneficial through product remanufacturing. Journal of Cleaner Production 13, 913-925.

Sundin, E., Lindahl, M., ljomah, W., 2009. Product Design for Product/Service Systems : design experiences from Swedish industry. Journal of Manufacturing Technology Management 20, 
723-753.

Sundin, E., Lindahl, M., Larsson, H., 2010. Environmental and Economic Benefits of Industrial Product/Service Systems, CIRP IPS² Conference, Linköping, Sweden, pp. 91-98 (http://liu.diva-portal.org/smash/record.jsf?pid=diva2:375724, access date 2010-12-08).

Tukker, A., 2004. Eight Types of Product-Service System: Eight Ways to Sustainability? Experiences from Suspronet. Business Strategy and the Environment 13, $246-260$.

Tukker, A., Tischner, U., 2006. Product-services as a research field: past, present and future. Reflections from a decade of research. Journal of Cleaner Production 14, 1552-1556.

Ulaga, W., Reinartz, W.J., 2011. Hybrid Offerings: How Manufacturing Firms Combine Goods and Services Successfully. Journal of Marketing 75, 5-23.

van den Hoed, R., 1997. A shift from products to services: an example of washing services. Proceedings 'Towards Sustainable Product Design', 2nd International Conference, London.

Werner, F., Althaus, H.J., Künniger, T., Richter, K., Jungbluth, N., 2007. Life Cycle Inventories of Wood as Fuel and Construction Material, Final report ecoinvent 2000 No. 9. EMPA. Swiss Centre for Life Cycle Inventories, Dübendorf, Switzerland.

Windahl, C., Lakemond, N., 2006. Developing integrated solutions: The importance of relationships within the network. Industrial Marketing Management 35, 806-818.

Wise, R., Baumgartner, P., 1999. Go Downstream: The New Profit Imperative in Manufacturing. Harvard Business Review 77, 133-141. 


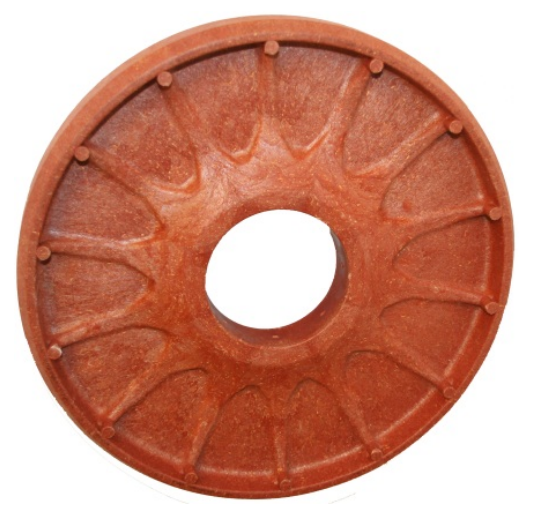

Figure 1: Core plugs for the paper mill industry.

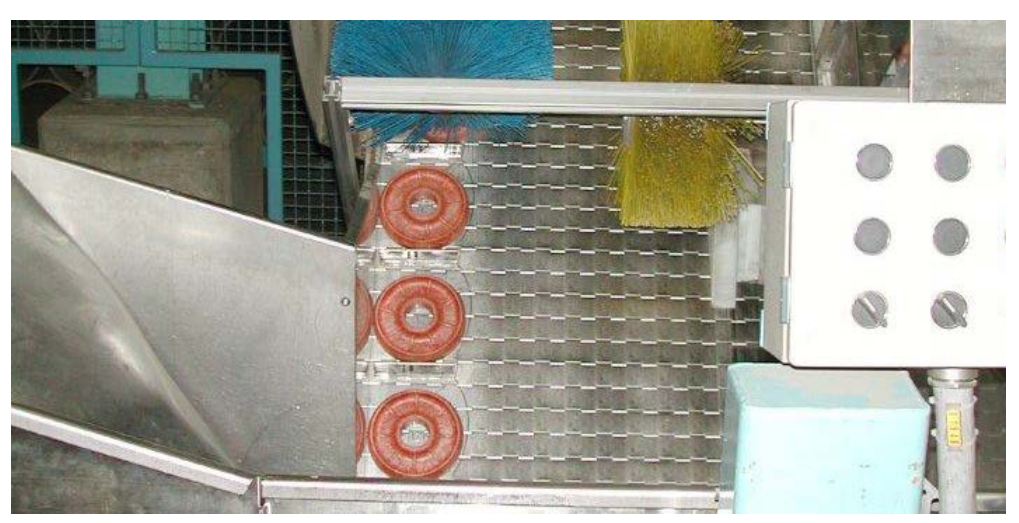

Figure 2: Cleaning of used core plugs at the paper mill company.

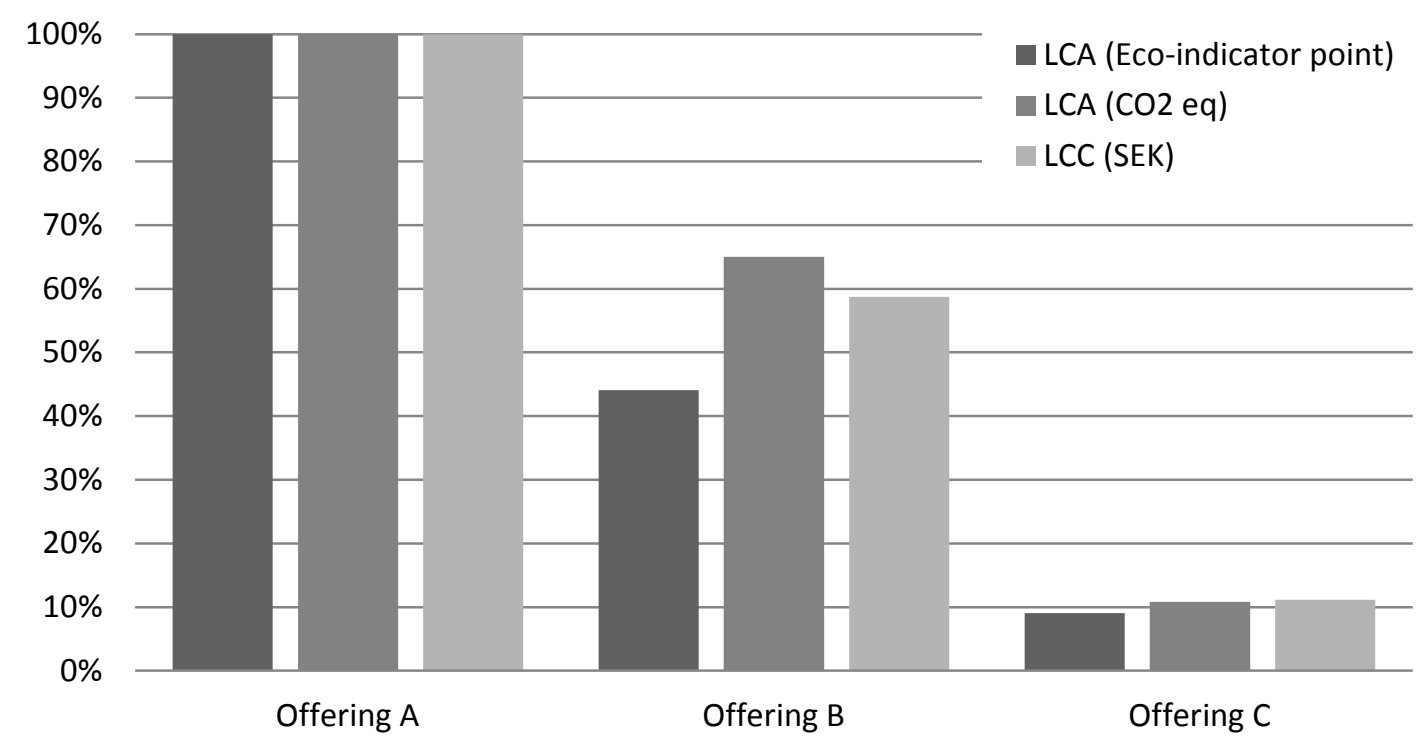

Figure 3: Summary of LCA and LCC for Case Study I. 


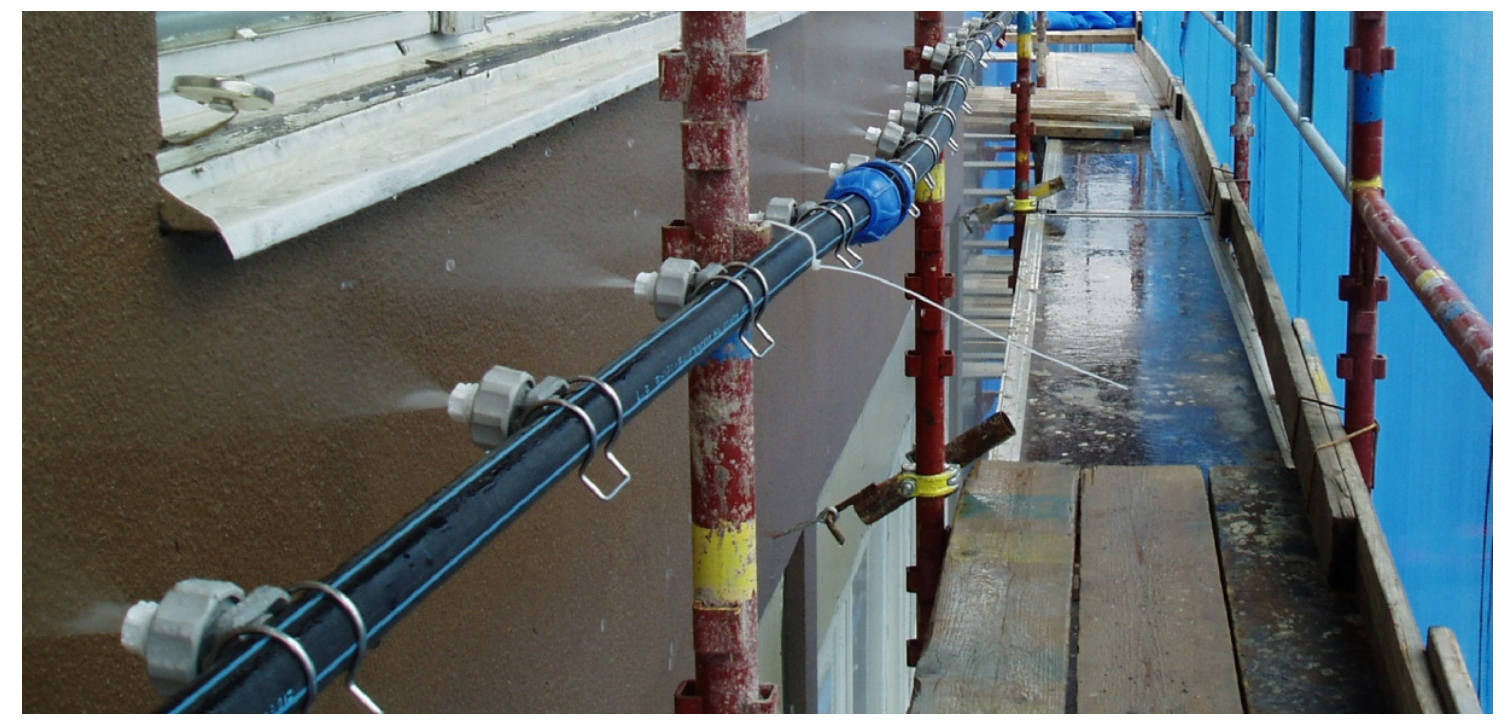

Figure 4: Application of QW on the building exterior by a piping system with nozzles.

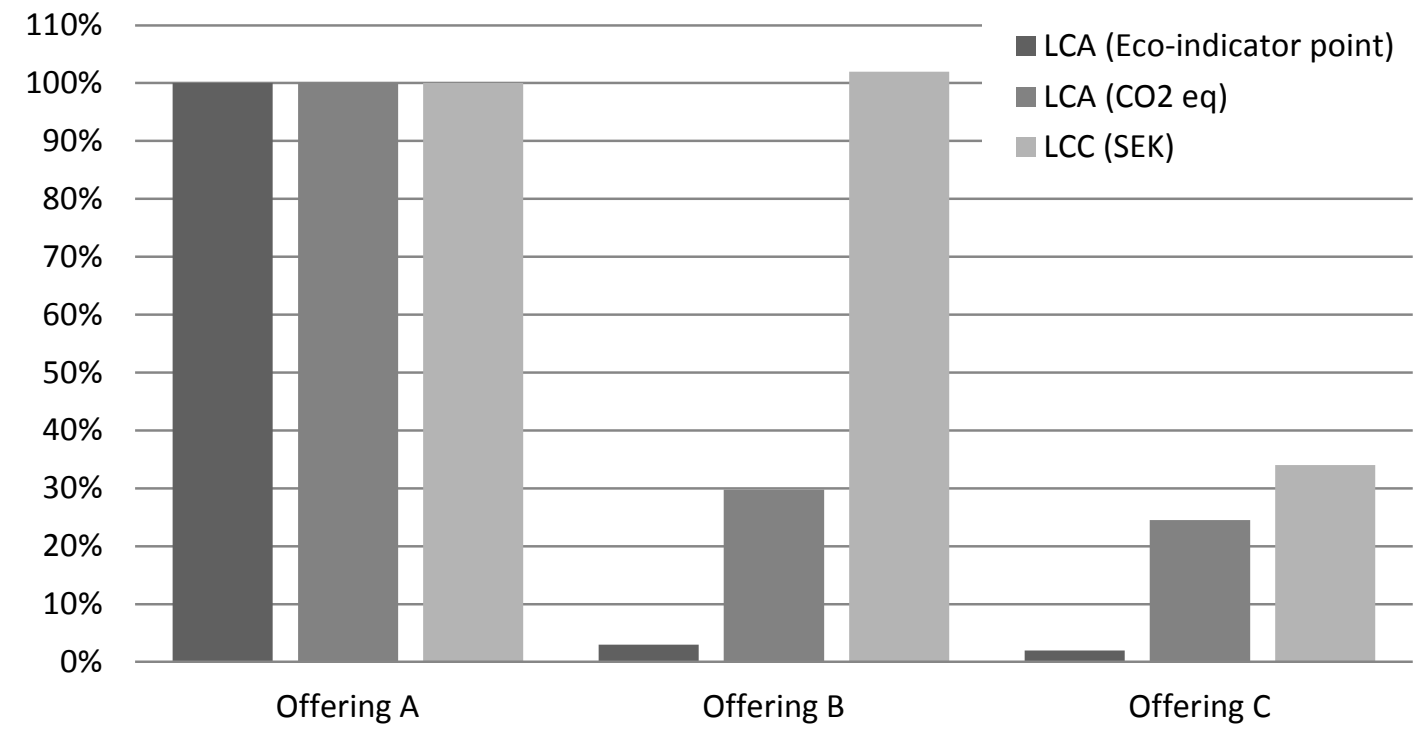

Figure 5: Summary of LCA and LCC for Case Study II. 


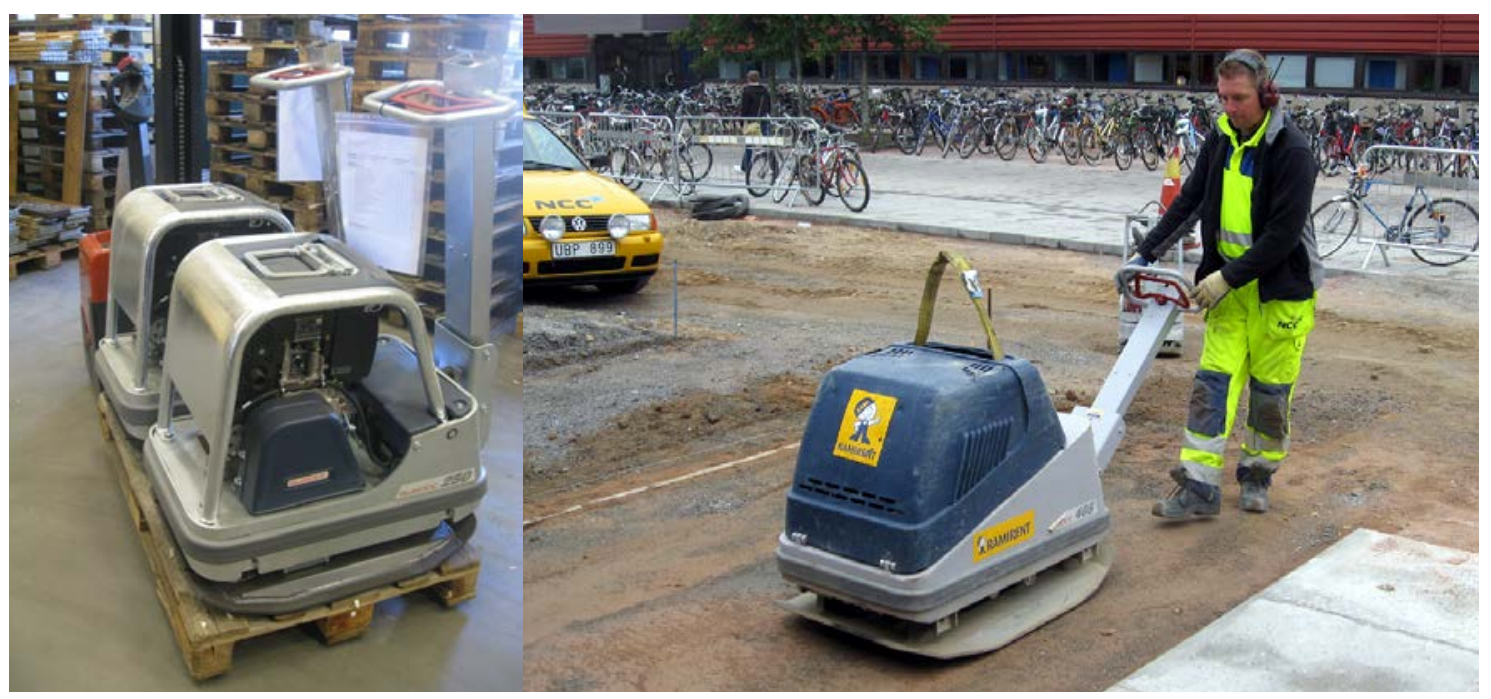

Figure 6: Examples of Swepac soil compactors and their usage.

\section{Swepac International $A B \Longleftrightarrow$ Rental firm $\Longleftrightarrow$ Construction firms}

Figure 7: The principal logistic flow of a Swepac soil compactor between, Swepac, the rental firm and the rental firm's customers (construction firms).

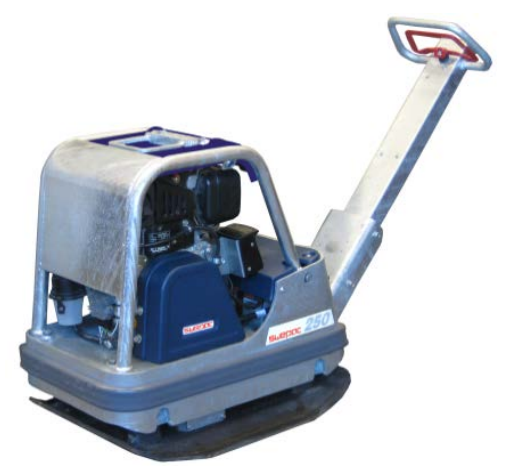

Figure 8: Soil compactor FB 250 used in this study. 


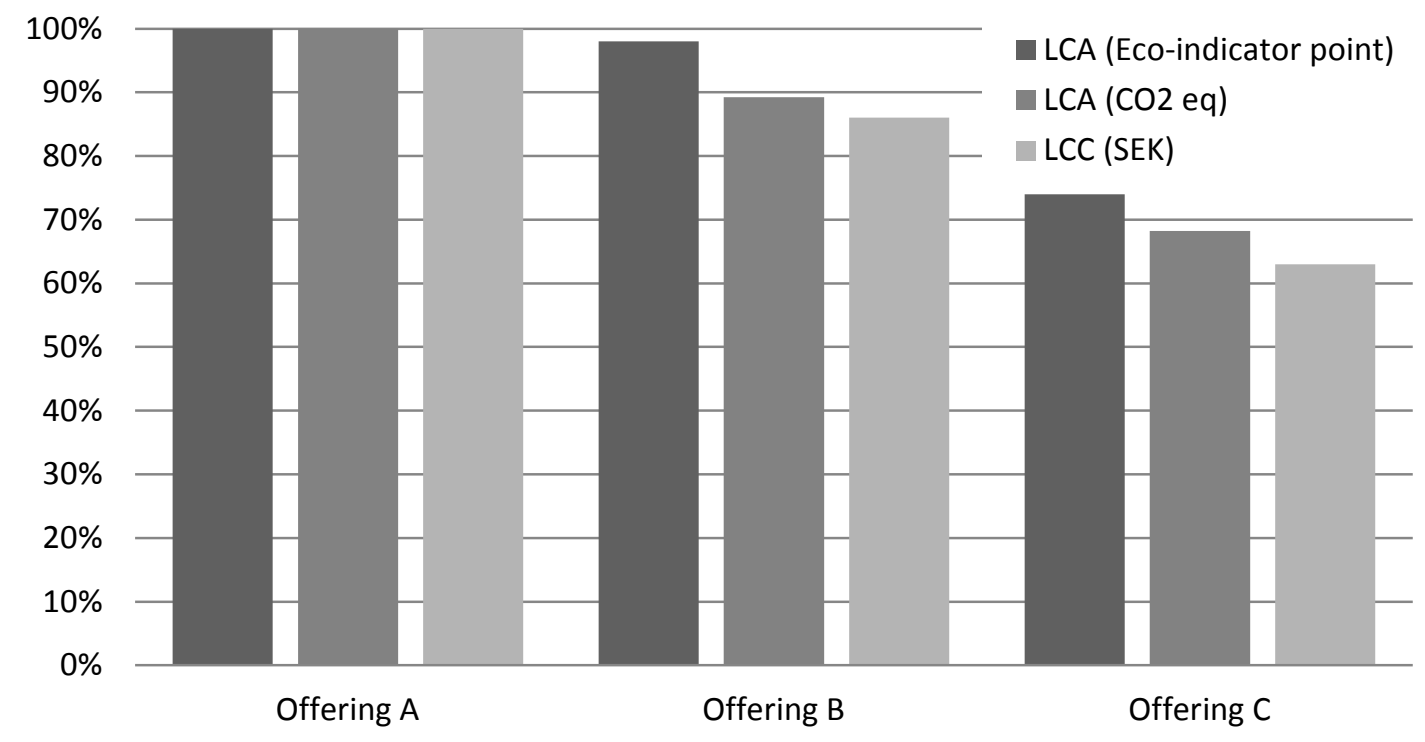

Figure 9: Summary of LCA and LCC for Case Study III. 
Table 1: Offerings compared in each industrial case study.

\begin{tabular}{|c|c|c|c|}
\hline Offering & Business model & $\begin{array}{c}\text { Current market } \\
\text { availability }\end{array}$ & Provided by \\
\hline A & Product sales & Yes & The case company or competitors \\
\hline B & Product sales or IPSO & No & - \\
\hline C & IPSO & Yes & The case company \\
\hline
\end{tabular}

“_" means "not relevant" because of the unavailability on the market.

Table 2: Summary offerings in Case Study I.

\begin{tabular}{|c|c|c|c|c|c|c|}
\hline Offering & $\begin{array}{c}\text { Business } \\
\text { model }\end{array}$ & $\begin{array}{c}\text { Current } \\
\text { market } \\
\text { availability }\end{array}$ & $\begin{array}{c}\text { Provided } \\
\text { by }\end{array}$ & $\begin{array}{c}\text { Used } \\
\text { material }\end{array}$ & $\begin{array}{c}\text { Product use times } \\
\text { at final customer }\end{array}$ & $\begin{array}{c}\text { Material } \\
\text { use times }\end{array}$ \\
\hline A & Product sales & Yes & Competitors & Virgin material & 1 & 1 \\
\hline B & Product sales & No & - & Polyplank material & 1 & 1 \\
\hline C & IPSO & Yes & Case company & Polyplank material & 5 & 3 \\
\hline
\end{tabular}

Table 3: Summary of offerings in Case Study II.

\begin{tabular}{|c|c|c|c|c|c|c|}
\hline Offering & $\begin{array}{c}\text { Business } \\
\text { model }\end{array}$ & $\begin{array}{c}\text { Current } \\
\text { market } \\
\text { availability }\end{array}$ & $\begin{array}{c}\text { Provided } \\
\text { by }\end{array}$ & $\begin{array}{c}\text { Washing } \\
\text { method }\end{array}$ & $\begin{array}{c}\text { Capacity } \\
{\left[\mathrm{m}^{2} / \text { day }\right]}\end{array}$ & $\begin{array}{c}\text { Drying time } \\
\text { [days] }\end{array}$ \\
\hline A & Product sales & Yes & Competitors & Detergents and high pressure & 300 & 6 \\
\hline B & Product sales & No & - & Qlean-method & 250 & 6 \\
\hline C & IPSO & Yes & Case company & Qlean-method & 300 & 0 \\
\hline
\end{tabular}

Table 4: Summary of offerings in Case Study III.

\begin{tabular}{|c|c|c|c|c|c|c|}
\hline Offering & $\begin{array}{c}\text { Business } \\
\text { model }\end{array}$ & $\begin{array}{c}\text { Current } \\
\text { market } \\
\text { availability }\end{array}$ & $\begin{array}{c}\text { Provided } \\
\text { by }\end{array}$ & $\begin{array}{c}\text { Surface } \\
\text { treatment }\end{array}$ & $\begin{array}{c}\text { Leasability [year] } \\
\text { (technical lifetime) }\end{array}$ & $\begin{array}{c}\text { Times of } \\
\text { Remanufacture }\end{array}$ \\
\hline A & Product sales & Yes & Case company & Varnished & 5 & 0 \\
\hline B & IPSO & No & - & Varnished & 6 & 1 \\
\hline C & IPSO & Yes & Case company & Galvanized & 8 & 1 \\
\hline
\end{tabular}

